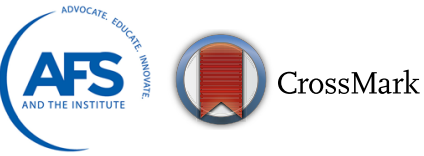

\title{
COMPLEXITIES IN THE ASSESSMENT OF MELT QUALITY
}

\author{
Martin Riestra $(\mathbb{B}$, Anton Bjurenstedt $(\mathbb{D})$, Toni Bogdanoff $(\mathbb{D}$, Ehsan Ghassemali $(\mathbb{C}$, and Salem Seifeddine $(\mathbb{D}$ \\ School of Engineering, Jönköping University, Jönköping, Sweden
}

Copyright $@ 2017$ The Author(s). This article is an open access publication

DOI 10.1007/s40962-017-0179-y

\begin{abstract}
If high-performance aluminium castings are to be produced, the melt quality needs to be properly assured. Multiple tests for melt quality assessment exist and have previously been analysed. In most studies, the techniques were used separately. In this work, reduced pressure, fluidity, Prefil and tensile tests were evaluated. A commercial

Bifilm index increased with addition level, but not correspondingly. Density index, Prefil and fluidity tests did not present significant variations, and tensile properties only deteriorated with the $50 \mathrm{wt} \%$ addition level. The investigated techniques provided information, but measuring the melt quality reliably remains a challenge.
\end{abstract} EN 46000 alloy was used as the base material with additions of 25 and 50 wt\% machining chips to degrade the melt quality. In reduced pressure and fluidity tests, oxides floated to the top of samples, decreasing the reliability.
Keywords: melt quality, reduced pressure test, fluidity, tensile properties, Prefil, hydrogen content

\section{Introduction}

One of the challenges that the aluminium casting industry faces today is related to the reduction in the variation in mechanical properties and to ensuring the quality of castings. These can be traced back to the quality of the melt. The presence of inclusions such as oxides (i.e. bifilms, spinel), carbides or refractory particles can be harmful to mechanical, physical and surface characteristics. ${ }^{1}$ Over the past years, multiple tools have been proposed for assessing the melt quality. Some of these tools include reduced pressure test (RPT), fluidity tests, Porous Disc Filtration Apparatus (PoDFA)/Pressure filtration (Prefil). ${ }^{2}$

The RPT consists of solidifying a melt sample under reduced pressure. According to Campbell, ${ }^{1}$ under such solidification conditions, bifilms will open up and unfurl, allowing their detection and leading to a reduction in density. The density difference between a sample solidified under atmospheric pressure and another under reduced pressure, in percent, is the density index. Hence, a low density index indicates a lower tendency to form pores. The bifilm index (BI) introduced by Dispinar and Campbell $^{3}$ is the sum of the maximum length of the pores in a cross section of a sample solidified under reduced pressure. A higher BI would indicate a lower melt quality.
Interestingly, the bifilms, portrayed as detrimental due to their pore/crack behaviour, can act as a composite material increasing strength. ${ }^{4}$

In the foundry industry, fluidity is referred to as the distance a liquid metal traverses before it stops due to solidification. By hindering the feeding and increasing the solid fraction, oxides and inclusions are expected to reduce fluidity. ${ }^{2}$ The effect of oxides and inclusions has been widely studied, resulting in decreasing fluidity values with increased oxide content, especially when low pouring temperatures have been used. ${ }^{2,5,6}$

The Prefil test uses a crucible with a porous filter disc at the bottom. The crucible with melt is preheated and placed in a pressure chamber. The chamber is pressurized when the starting temperature is reached, forcing the material through the porous filter disc. The material passing through the filter disc is collected on a scale, and the data are logged as Prefil curves, showing mass versus time. ${ }^{7}$ It has been discussed that the effectiveness of the technique is highly related to the filter used. ${ }^{8}$

The effectiveness of these techniques has in general been studied separately. ${ }^{4,5,7}$ In addition, results are generally difficult to compare and the relation to tensile properties 
has not been always reported. Regarding the analysis of tensile results, Green and Campbell ${ }^{9}$ introduced the use of Weibull distributions to describe the scatter. Tyryakioglu and Hudak ${ }^{10}$ proposed a procedure for calculating and analysing 2-parameter Weibull fits. In it, $\sigma_{0}$, scale parameter representing the $\sigma$ at which $62.8 \%$ of the population of samples has failed, and $m$, shape parameter or Weibull modulus, are reported along with $R^{2}$ goodness-of-fit criteria and confidence limits for the estimated parameters.

This study aims to critically assess some of these commonly proposed techniques to measure the melt quality. To produce relevant and fully comparable data, reduced pressure, fluidity, Prefil and tensile tests on the same melts were performed. Three melts with different degrees of machining chips additions were prepared to achieve different and controlled cleanliness levels.

\section{Materials and Experimental Procedure}

The base condition (L00) was produced by melting commercial EN 46000 alloy in a resistance furnace. The other two were produced by 25 and $50 \mathrm{wt} \%$ of machining chips additions to degrade the melt quality (L25 and L50, respectively). Additions were performed by introducing pressed pucks of the chips in the bottom of the furnace together with the alloy ingots. For each of the three conditions, $50 \mathrm{~kg}$ of melt was prepared. To ensure the same chemical composition for the three conditions, the first melt cast was the L50. Based on the measured chemical composition for this condition (Table 1), the chemical composition of the L00 and L25 melts was adjusted by using suitable master alloys. The melt, held at $765^{\circ} \mathrm{C}$, was only stirred when additions were made to ensure proper dissolution. To simulate observed industrial practices, the melt was skimmed only once after melting. The relative humidity of the room was measured near the furnace. Chemical composition was measured by Optical Emission Spectroscopy using a Spectromaxx LMX06.

Reduced pressure test (RPT) samples weighing $77 \pm 6 \mathrm{~g}$ were scooped from the melt with boron nitrate-coated stainless steel cups. A total of 10 samples (5 at a reduced pressure of 80 mbar, 5 at atmospheric pressure) were taken in pairs. Hydrogen content was measured when the RPT tests were sampled using Alspek H. Density index was calculated based on the densities of the atmospheric and reduced pressure samples, measured using the Archimedes principle. The BI was determined from cross sections of reduced pressure test samples. The maximum pore lengths were measured with the Olympus Stream Motion Desktop 1.9.1 software on $600 \mathrm{dpi}$ resolution scans of the cross sections after grinding. In this study, the lower detection limit was set to porosities with an area equivalent to a circle diameter of $0.2 \mathrm{~mm}$. The measured BI index was divided by the measured area to determine the bifilm quantity.

Five spiral fluidity tests (provided by Bryne AB; Figure 1) were taken by manually filling the cup above the spiral and allowing the melt to flow in the spiral once the temperature reached to $720{ }^{\circ} \mathrm{C}$. Fluidity values were calculated as the distance traversed within the mould. For the three Prefil measurements, $2-\mathrm{kg}$ samples were taken by pouring melt into 70-mm-diameter steel cylindrical moulds. The top part of the cylinders was then cut to produce $1.4 \mathrm{~kg}$ samples that were later re-melted in an induction furnace and poured into the Prefil equipment. An online model compensating for the variation of filter permeability was used allowing for the calculation of a melt cleanliness (MC) number, quantifying the melt quality based on the build-up of the inclusions cake on the filter. A low MC indicates a clean melt and vice versa.

Tensile test bars were cast in a tilting steel mould preheated to $250{ }^{\circ} \mathrm{C}$. The casting temperature of the melt was $720{ }^{\circ} \mathrm{C}$. Each casting produced eight tensile specimens (Figure 1). To ensure laminar flow and evaluate solely the influence of melt quality and minimize casting-related defects, according to MAGMAsoft (v. 5.3) simulations, a tilting period of $7 \mathrm{~s}$ was selected. Twenty-four specimens from each condition, machined to a gauge length of $34 \mathrm{~mm}$ and a diameter of $9 \mathrm{~mm}$, were tested with a Zwick/Roell Z100 machine equipped with a $100 \mathrm{kN}$ load cell. The samples were tested until fracture using a constant strain rate of $0.5 \mathrm{~mm} / \mathrm{min}$. The strain was measured using a clip-on extensometer. The presented results were calculated omitting the two best and worst performers selected according to their quality index, determined by using the formula

Table 1. Melt Composition for the Tested Conditions

\begin{tabular}{llllllllllll}
\hline & $\mathrm{Si}$ & $\mathrm{Fe}$ & $\mathrm{Cu}$ & $\mathrm{Mn}$ & $\mathrm{Mg}$ & $\mathrm{Cr}$ & $\mathrm{Ni}$ & $\mathrm{Zn}$ & $\mathrm{Ti}$ & $\mathrm{Sr}$ & $\mathrm{Al}$ \\
\hline L00 & 8.46 & 0.58 & 1.84 & 0.36 & 0.27 & 0.02 & 0.02 & 0.91 & 0.02 & 0.03 & $\mathrm{Bal}$ \\
$\mathrm{SD}$ & 0.053 & 0.010 & 0.197 & 0.012 & 0.000 & 0.000 & 0.001 & 0.058 & 0.001 & 0.004 & \\
L25 & 8.49 & 0.64 & 2.16 & 0.38 & 0.28 & 0.02 & 0.02 & 1.03 & 0.03 & 0.03 & Bal \\
$\mathrm{SD}$ & 0.095 & 0.010 & 0.021 & 0.006 & 0.015 & 0.001 & 0.001 & 0.010 & 0.003 & 0.006 & \\
L50 & 8.49 & 0.61 & 2.09 & 0.38 & 0.32 & 0.03 & 0.02 & 0.99 & 0.03 & 0.03 & Bal \\
$\mathrm{SD}$ & 0.006 & 0.010 & 0.026 & 0.006 & 0.012 & 0.001 & 0.001 & 0.006 & 0.000 & 0.002 & \\
\hline
\end{tabular}



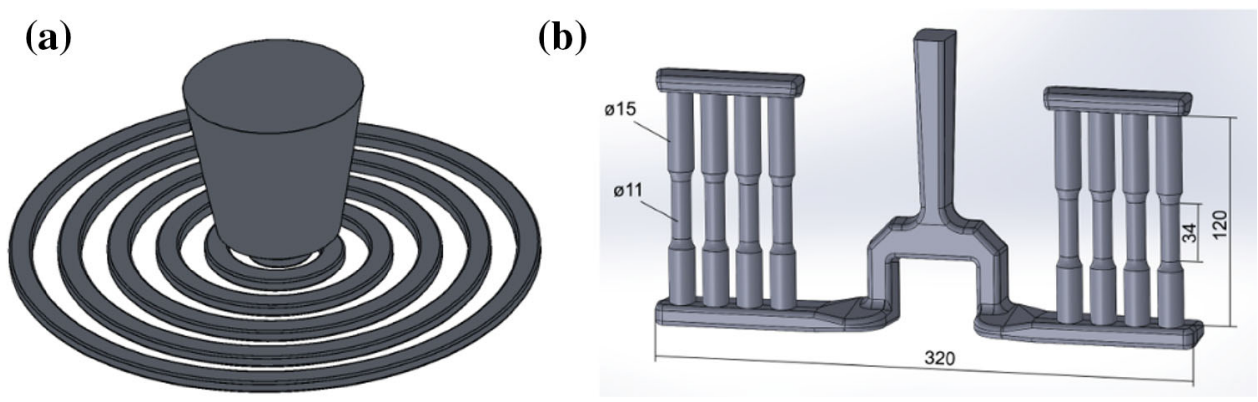

Figure 1. (a) Fluidity test geometry and (b) tilting tensile samples geometry.

proposed in Reference 11. Fitting to 2-parameter Weibull distributions was performed by the maximum likelihood method, following the guidelines by Tiriakioglu and Hudak. $^{10}$

Selected samples from RPT, fluidity and tensile specimens were mounted and polished following standard practices for optical microscopy. The porosity at the tip of fluidity tests was characterized with image analysis over a total area of at least $250 \mathrm{~mm}^{2}$. Area fraction of defects on the fracture surfaces of the best, worst and average performers in terms of quality index for each condition was characterized, following the procedure in Reference 12 on SEM images of the fracture surface.

\section{Results}

Melt compositions for the three conditions, referred to as L00, L25 and L50, according to the wt\% level of chip additions, are given in Table 1 .

\section{Melt Quality Characterization}

The main results for the tested techniques are shown in Figure 2. From the RPT, it was observed that the density index (DI) did not change significantly, and the scatter only increased for the L25 condition. The trend for the bifilm index (BI) was to increase with cutting chips additions, but if the standard deviation is considered, this change was not significant. The measured hydrogen content was observed to be the same for the L00 and L25 castings and to decrease for the L50 casting. Relative humidity levels during casting were 39, 35 and 48\% for L00, L25 and L50, respectively. Fluidity and Prefil tests did not show significant variation. The compensated Prefil curves were virtually the same for the L25 and L50. According to the MC number ranges given by the Prefil service provider, ${ }^{13}$ all three melts would be considered "clean" in an industrial environment. The average tensile strength and elongation were only significantly affected with the addition of $50 \mathrm{wt} \%$ of machining chips.

Further analysis of the tensile test results by fitting to Weibull distributions is presented in Figure 3 and Table 2. Good fit to 2-parameter Weibull distributions was observed for both UTS and elongation values for conditions LO0 and L25, but only for the UTS values of the L50 condition. The Weibull modulus decreased with the cutting chips addition. While the same scale parameter was observed for the L00 and L25 conditions, the L50 condition presented a lower value. The Weibull plots of L00 and L25 were grouped together and at higher UTS and elongation values compared to the L50 condition. (a)

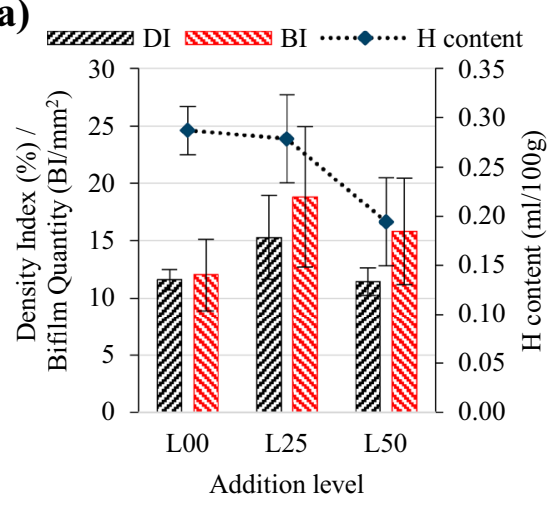

(b)

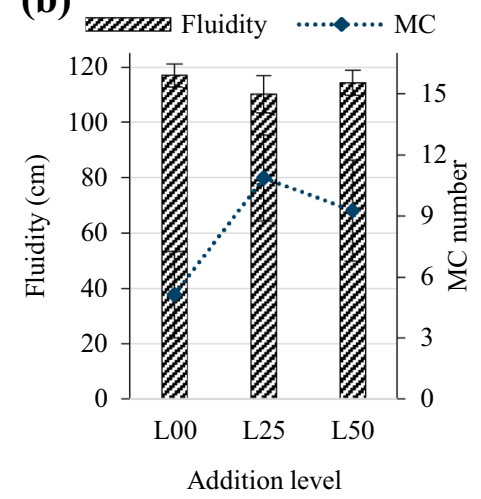

(c)

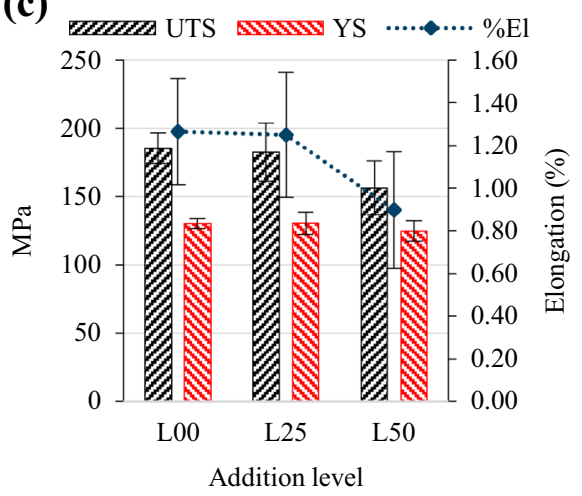

Figure 2. (a) Density index (DI), bifilm index (BI) and hydrogen content, (b) fluidity and Prefil melt cleanliness number (MC), (c) ultimate tensile strength (UTS), yield strength (YS) and \% elongation for the three conditions tested. 

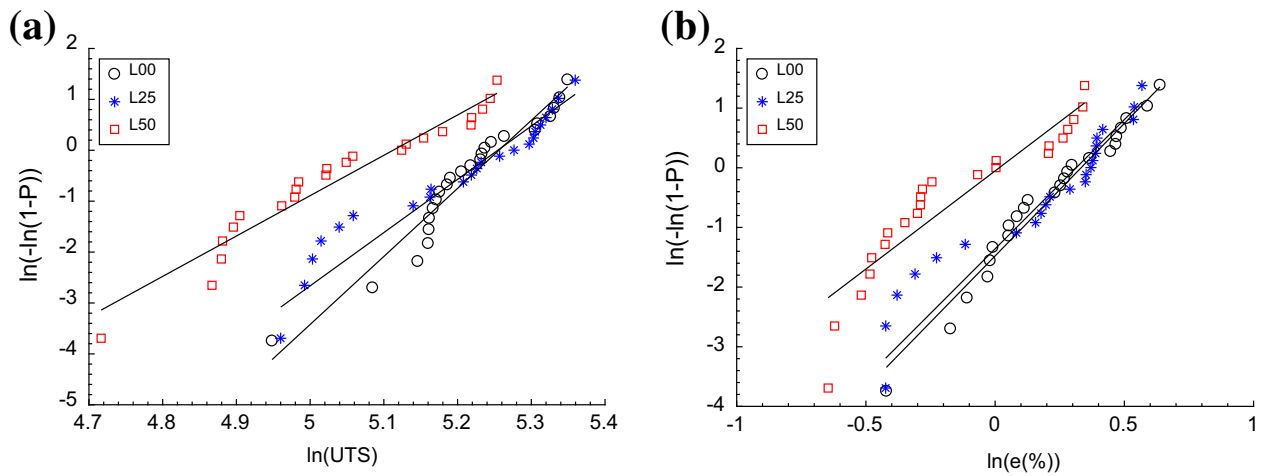

Figure 3. Weibull plots of (a) UTS and (b) \% elongation for the three conditions tested.

Table 2. Statistical Results on the Weibull Fits for the Three Conditions Tested

\begin{tabular}{|c|c|c|c|c|c|c|c|c|c|c|c|c|}
\hline \multirow[t]{2}{*}{ UTS } & \multirow[t]{2}{*}{$n$} & \multicolumn{2}{|c|}{ Plotting position } & \multicolumn{2}{|c|}{ Parameter estimates } & \multicolumn{3}{|c|}{ Goodness of fit } & \multicolumn{4}{|c|}{$95 \%$ Confidence limits } \\
\hline & & $a$ & $b$ & $m$ & $\sigma_{0}$ & $R_{(0.05)}^{2}$ & $R^{2}$ & Weibull? & $m$ & & $\sigma_{0}$ & \\
\hline LOO & 24 & 0.439 & 0 & 13.37 & 192 & 0.903 & 0.940 & Yes & 9.2 & 20.8 & 167.6 & 223.9 \\
\hline L25 & 23 & 0.434 & 0 & 10.47 & 191 & 0.901 & 0.933 & Yes & 7.1 & 16.4 & 166.9 & 224.3 \\
\hline L50 & 23 & 0.434 & 0 & 7.93 & 166 & 0.901 & 0.942 & Yes & 5.4 & 12.4 & 144.8 & 194.6 \\
\hline \multirow[t]{2}{*}{$e(\%)$} & \multirow[t]{2}{*}{$n$} & \multicolumn{2}{|c|}{ Plotting position } & \multicolumn{2}{|c|}{ Parameter estimates } & \multicolumn{3}{|c|}{ Goodness of fit } & \multicolumn{4}{|c|}{$95 \%$ Confidence limits } \\
\hline & & $a$ & $b$ & $m$ & $\varepsilon_{0}$ & $R_{(0.05)}^{2}$ & $R^{2}$ & Weibull? & $m$ & & $\varepsilon_{0}$ & \\
\hline LO0 & 24 & 0.439 & 0 & 4.44 & 1.39 & 0.903 & 0.970 & Yes & 3.0 & 6.9 & 1.2 & 1.6 \\
\hline L25 & 23 & 0.434 & 0 & 4.33 & 1.37 & 0.901 & 0.920 & Yes & 2.9 & 6.8 & 1.2 & 1.6 \\
\hline L50 & 23 & 0.434 & 0 & 3.29 & 1.02 & 0.901 & 0.858 & No & 2.2 & 5.1 & 0.9 & 1.2 \\
\hline
\end{tabular}

\section{Microstructural Characterization}

Upon analysis of the microstructure of RPT and fluidity tests, it was noticed that folded oxides with air entrapment concentrated towards the top of the samples (Figure 4a, d, g). For RPT samples, there was a marked boundary between the oxide layers and the remaining sample. These oxides were only found above a band of big round porosity in L25 and L50 conditions in the reduced pressure samples (dotted line in Figure 4e, h). The voids below these bands mostly had the appearance of shrinkage porosity. The atmospheric pressure samples also presented accumulation of folded oxides on the top. For these samples, no big pores were present on the boundary separating oxides from the rest of the sample. In the fluidity tests, these folded oxides were found on the top of the feeder sections for the spiral (Figure $5 \mathrm{~d}$ ). The tip of the tests displayed round-shaped porosity of various sizes (Figure $5 \mathrm{a}, \mathrm{b}, \mathrm{c}$ ).

The characterization of the porosity found in the tip of fluidity tests is found in Table 3. It can be observed that the addition of machining chips reduced both the pore area fraction and the size of the pores, while the number of pores increased. The variation in porosity size was also reduced.
Investigation of polished untested tensile samples revealed that the L00 condition presented mostly porosity, identified as shrinkage and not observed to be connected to other type of defects. Only a reduced number of possible oxide films were observed, with sizes that were smaller than the porosity. In L25 samples, most of the porosities observed were connected to old oxides and only some pores were observed isolated from these films in the polished cross section. As the polished section represents only part of the pores, these could be connected to oxide films below the observed section. Most of porosities in L50 samples were associated with folded oxides. Both L25 and L50 conditions also presented big inclusion particles reaching sizes up to $500 \mu \mathrm{m}$ in the longest length.

Fracture surface examination of tensile tested samples revealed oxides/inclusions on some L00 samples, which were identified as the worst performers according to the quality index. All the other samples presented shrinkage porosity, identified as such since dendrites could be observed in the pores. As of the L25 and L50 conditions, different size and distributions of thick oxide layers and/or inclusions were observed for all samples. Samples with bigger areas of oxide layers presented in general smaller amount of shrinkage-related porosity. Figure 6 presents an 
example of the selection process along with the correlation between UTS and area fraction of defects.

Upon examination of the polished fracture samples, in L00 samples porosity was observed both at the crack propagation path and in the areas below it. The L25 and L50 samples presented old oxide films both at the fracture profile as below it. In some cases, for the L50 condition these oxide films accounted for more than $50 \%$ of the crack
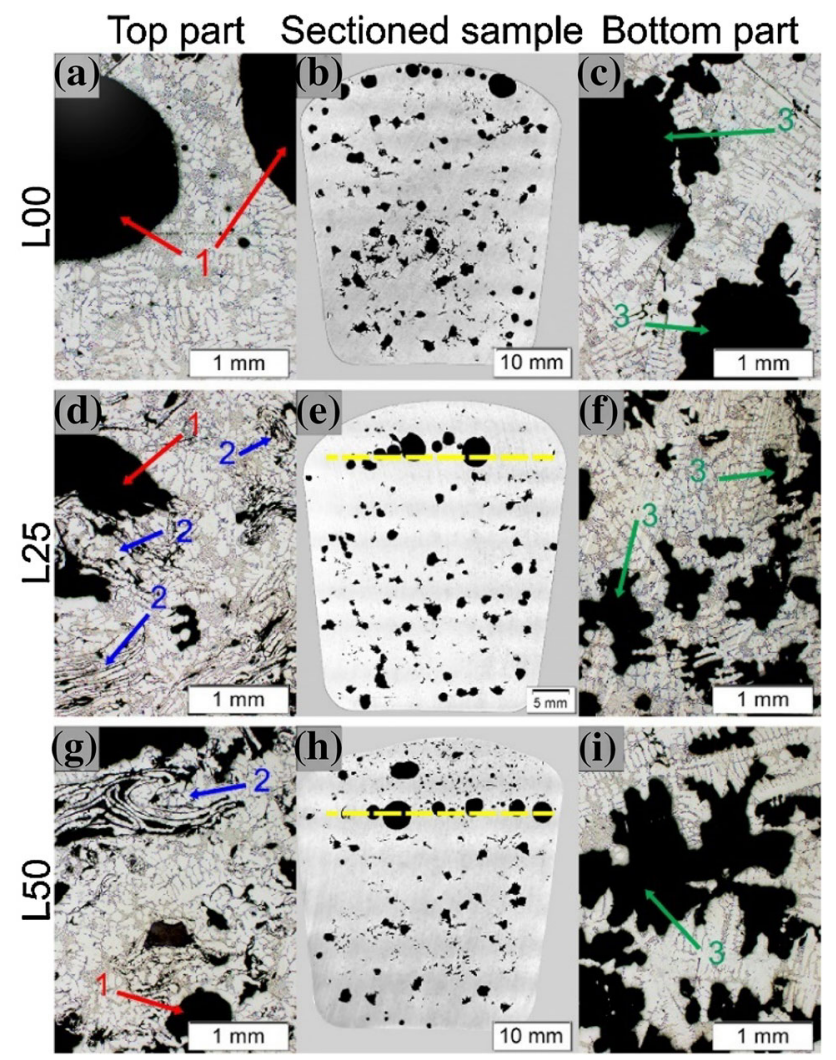

Figure 4. Typical RPT microstructures for sectioned (b) L00, (e) L25 and (h) L50 samples. (a), (d) and (g) corresponding to the top area of L00, L25 and L50, respectively, and (c), (f) and (i) to the bottom area. Arrows marking (1) gas pores, (2) folded oxides, (3) shrinkage pores and dashed line marks the oxide boundary. propagation length. Examples of the observed path are found in Figure 7.

\section{Discussion}

\section{Reduced Pressure Test}

Based on the reviewed literature, it was expected that increasing additions of cutting chips would result in an increase in the dome-shaped top of the samples due to more films opening up. As presented in Figure 2 a, BI did not increase with additions. The floatation of oxides has been observed by Di Sabatino et al. ${ }^{6}$ and is also discussed by Campbell, ${ }^{14}$ considering that the separation by floatation will be slow due to bifilms having almost neutral buoyancy. Considering the amount and the apparent shape of the oxides observed, an increase in buoyancy due to a bigger surface area could explain the findings. From the microstructural analysis, numerous folded oxides with what is presumed to be air entrapments were found. Against what would be expected from the application of reduced pressure, these oxides remained folded during solidification and did not unfurl as proposed in the literature. ${ }^{1}$ As the oxides are essentially solid, it seems reasonable that they could float to the top and cool down before having time to unfurl as proposed by Campbell. ${ }^{14}$ The observed band of bigger round pores below these old oxides would support such an explanation: when the hydrogen is rejected from the solidifying areas, it would diffuse towards the encapsulated films of air below these oxides and expand them. ${ }^{3}$ As the top part of the sample would already be partially solid, the expansion could only take place towards the liquid, hence creating the porosity band below the oxide layer. The suggested mechanism is presented in Figure 8. The location of these films at the top of the samples (both reduced and atmospheric pressure) leads the authors to believe that, regardless of the amount of bifilms present in the melt, these old oxides prevented the unfurling of such bifilms, reducing the reliability of the test. Also, according to Reference 8, the action of shrinkage can be considered negligible. The presented results show otherwise (Figure 4c, f, i), suggesting that the technique is not always acting under the specified assumptions. The loss of reliability is twofold; neither possible

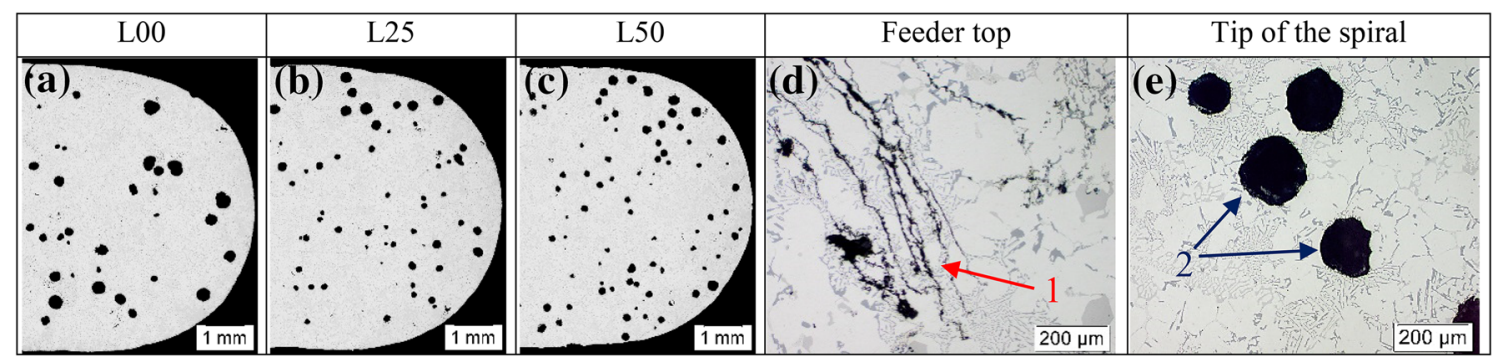

Figure 5. Typical fluidity test microstructures corresponding to (a) L00 condition, (b) L25 condition, (c) $L 50$ condition tips of the spiral. (d) Top of the fluidity test feeder and (e) detail around pore in $L 50$ sample. Arrows marking (1) folded oxide and (2) gas pore. 
Table 3. Porosity Characteristics in the Tip of Fluidity Tests

\begin{tabular}{lllllll}
\hline & $\begin{array}{l}\text { Pore area } \\
\text { fraction }(\%)\end{array}$ & $\begin{array}{l}\text { Pore per } \\
\mathrm{mm}^{2}\end{array}$ & $\begin{array}{l}\text { Average equivalent. } \\
\text { circular diameter }(\mu \mathrm{m})\end{array}$ & $\begin{array}{l}\text { Max. equivalent. circular } \\
\text { diameter }(\mu \mathrm{m})\end{array}$ & $\begin{array}{l}\text { Average of max. pore } \\
\text { length }(\mu \mathrm{m})\end{array}$ & $\begin{array}{l}\text { Max. pore } \\
\text { length }(\mu \mathrm{m})\end{array}$ \\
\hline L00 & 3.81 & $1 \pm 0.07$ & $196 \pm 105$ & 644 & $240 \pm 112$ & 920 \\
L25 & 3.57 & $1.5 \pm 0.03$ & $161 \pm 65$ & 389 & $192 \pm 69$ & 419 \\
L50 & 2.92 & $1.5 \pm 0.22$ & $145 \pm 65$ & 429 & $180 \pm 75$ & 501 \\
\hline
\end{tabular}
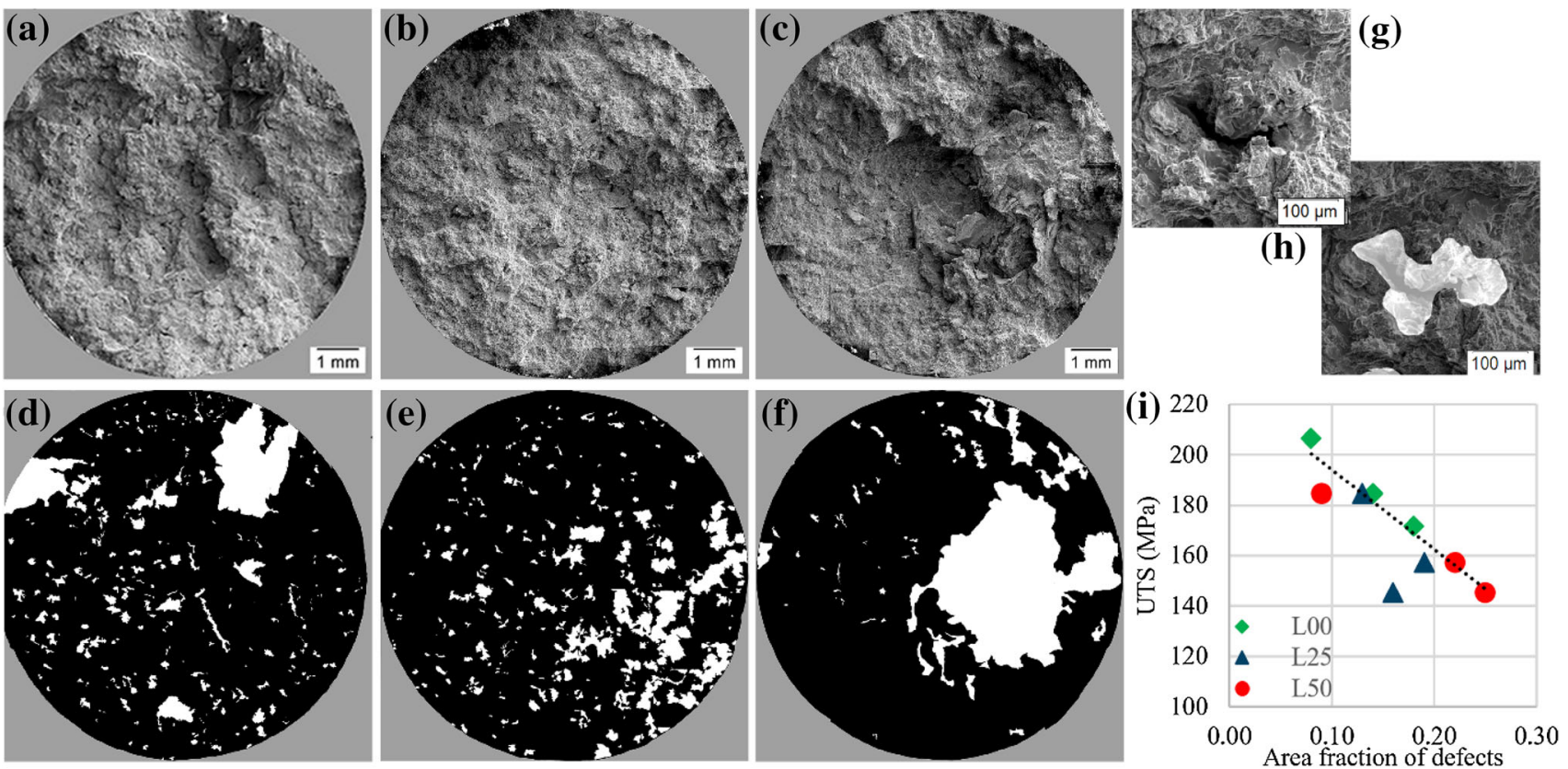

Figure 6. Example of fracture surface of (a) LOO, (b) L25, (c) L50 samples, binary selection of defects: (d) L00, (e) L25, (f) L50. (g) Porosity detail and (h) corresponding selection in LOO sample. (i) UTS versus area fraction of defects for the three conditions tested. The dotted line offered as guide to reader.
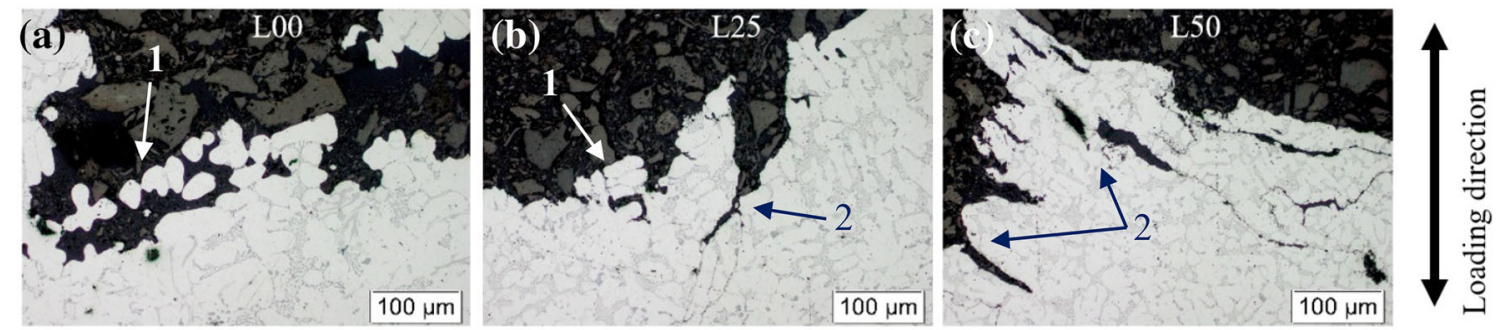

Figure 7. Typical fracture profiles of (a) $L 00$ samples, (b) $L 25$ samples and (c) $L 50$ samples. (1) Porosity and (2) oxide film. Loading direction is in vertical direction respect to the pictures.

bifilms, nor the (in this case known) the presence of old oxides were detected.

The lower hydrogen content in the L50 melt could also explain the lower DI and BI observed for this condition. This condition had comparatively more oxides which could act as nucleation sites. If this is coupled with lower hydrogen available to expand bifilms and a thicker oxide layer on top of the RPT, the chances of smaller bubbles forming is higher. These smaller bubbles might be below the detection limit therefore reducing the total length of bifilms accounted for. Under such an assumption, the RPT would be unreliable when hydrogen content is low in the melt. As the unfurling of bifilms would need both hydrogen and bifilms, ${ }^{3}$ pinpointing the origin of the DI or BI variation to low hydrogen or high oxide films content would be delusive. 


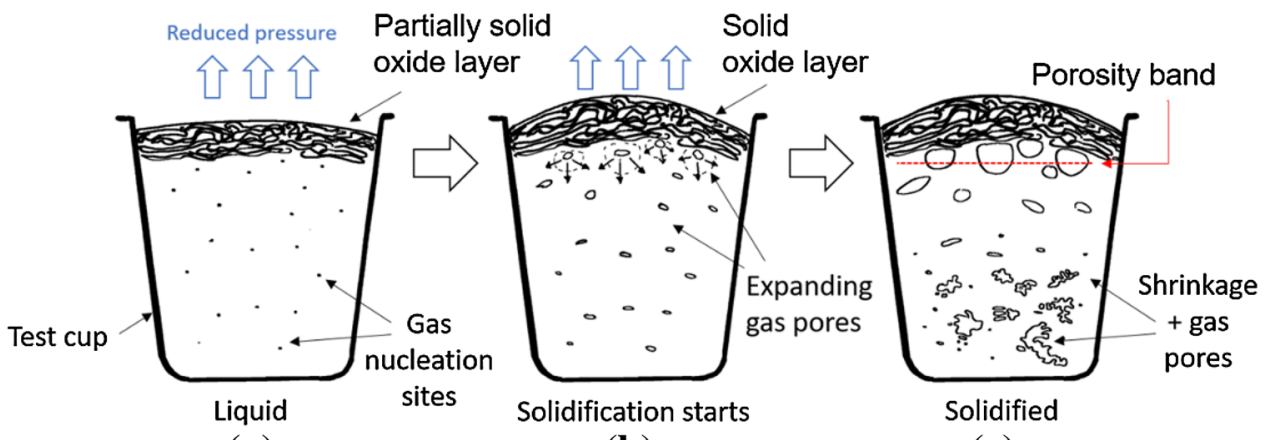

(a)

(b)

(c)

Figure 8. Suggested solidifying mechanism for the RPT for a melt with high oxide content: (a) sample before solidification starts, (b) start of solidification and (c) solidified sample.

\section{Fluidity and Prefil}

Analysis of the cups above the spirals revealed thick old crumpled oxides at the top. According to Timelli and Bonollo, ${ }^{5}$ a decrease in fluidity is expected with the addition of scrap due to the decrease in the critical solid fraction at the flow tip. As the fluidity tests were gravity-fed, if the oxides were found at the top, they did not take part in the overall flow as they were not mixed in the bulk of the melt, thus resulting in the observed absence of fluidity change. These results were found to be in good agreement with similar experiments by Di Sabatino. ${ }^{6}$ This would imply a loss in reliability of the test as a measure of oxide inclusion or melt quality, but, would mean that a relatively accurate determination of the fluidity of a clean melt could result from this technique. The opposite effect can be expected for melts with grain refinement additions, where settlement of particles is expected. ${ }^{15}$ If such settlement occurs during holding in the analysis cup, a loss of fluidity can be expected due to these particles agglomerating in the ingate to the spiral. As the Prefil tests relies on a combination of pressure difference and gravity for forcing the melt through the filter, the floatation of thicker oxides would also explain the lack of change observed. As these oxides would only form a cake on the filter after most of the melt has gone through, the change in the mass versus time curve can be expected to be minimal. While the observed trend is similar to that in Reference 6, the minimal difference in the present results yielded this technique useless under the tested conditions. The complementary PoDFA analysis would be helpful to interpret these Prefil results but would miss the point of using it as an online quality characterization tool.

The change in the distribution of porosity observed in the tip of the fluidity tests (Table 3) agreed with the proposed mechanism of increased presence of nucleation sites for porosity with the increase in oxide content. ${ }^{1,14,16}$ With a similar $\mathrm{H}$ content, the relatively clean L00 melt, having less oxides and inclusion content, provided less nucleation sites for the formation of porosity, resulting in bigger pores. In this sense, a certain amount of oxides and inclusions could be considered beneficial to effectively reduce maximum porosity size and distribute it into a larger amount of smaller porosity. The smaller difference in porosity size and distribution between L25 and L50 conditions could be related to a saturation of nucleation sites with the $25 \mathrm{wt} \%$ addition of machining chips, not leading to increased porosity nucleation events with further addition of chips (L50). Alternatively, it could be due to the decrease in hydrogen content for the L50 casting, balancing with the higher amount of oxides and inclusions.

\section{Tensile Test}

The correction of the castings' chemical composition allowed for evaluation of the tensile properties solely related to the influence of defects, be it pores, oxides or other inclusions. While the average values for UTS, YS and elongation did not suffer any change with addition of $25 \mathrm{wt} \%$ machining chips, the scatter increased noticeably. This was expected to be due to a wider variation of defects in the fracture surface. The analysis of defect area fraction, based on only a selection of samples, showed good correlation to UTS as proposed by Cáceres and Selling. ${ }^{12}$ The change of defects, mostly porosity in L00 samples to an oxide-porosity mix in the L25 samples while still maintaining similar defect area fraction, was also found to be in agreement with Cáceres and Selling's ${ }^{12}$ results, showing that the type of defects seems to be less significant compared to area fraction. As the characterization of defects in the fracture surface is somehow arbitrary, a conservative approach was followed, selecting only areas that were clearly considered a defect. The consequence of such an approach could be an underestimation of the defect area fraction.

When considering the parameters obtained from the Weibull distribution fitting, conditions L00 and L25 would be virtually undistinguishable. With the same scale parameter $\left(\sigma_{0}^{\mathrm{L} 00}=192, \sigma_{0}^{\mathrm{L} 00}=191\right)$, there would only be a slight difference in the spread of the data due to the different shape parameters $\left(m^{\mathrm{L} 00}=13.37, m^{\mathrm{L} 25}=10.47\right)$. This was 
also observed with the analysis of average and standard deviation. According to Green and Campbell, ${ }^{9}$ from the scale parameter, these two melts would be considered to have similar distributions of fracture strength and the same quality. The same observation could be concluded from the \%elongation analysis. With respect to the fitting through a 2-parameter Weibull distribution, flaws were found in best, worst and average performers (as shown in Figure 6e), precluding the use of a threshold value. Considering Campbell's classification of Weibull moduli values, ${ }^{1}$ LO0 and L25 conditions would correspond to the low end of the gravity die casting interval and the L50 to a high-pressure die casting value. Eisaabadi et al. studied the effect of $\mathrm{Fe}$ addition $^{17}$ and filtering ${ }^{18}$ on Weibull modulus, reporting decreases of $54 \%$ in modulus of UTS with the increase in $\mathrm{Fe}$ content from 0.09 to $0.85 \mathrm{wt} \%$, and $53 \%$ through pouring without filter a melt degraded by mechanical stirring. Comparatively, the present results show a decrease in Weibull module of UTS of 22 and $41 \%$ for the L25 and L50 melts with respect to the relatively clean L00 melt.

\section{Conclusions}

Reduced pressure, fluidity, Prefil and tensile tests have been performed on a base EN 46000 alloy and with 25 and $50 \mathrm{wt} \%$ machining chip additions. The following conclusions can be drawn:

- The techniques available to assess the melt quality are inadequate, requiring further analysis for reliable interpretation of results.

- The floatation of oxides affected the working principle of RPT, fluidity and Prefil tests, resulting in "false positives" as the values reported for degraded melts did not significantly differ from the clean melt values.

- Addition of $25 \mathrm{wt} \%$ machining chips to the melt resulted in a decreased amount of maximum pore size due to increased number of nucleation sites in fluidity tests. The $50 \mathrm{wt} \%$ addition, coupled with the decrease in hydrogen content, resulted in a reduction in pore area fraction.

- While addition of $25 \mathrm{wt} \%$ machining chips did not degrade average tensile strength and elongation, levels of $50 \mathrm{wt} \%$ addition noticeably did.

- Weibull statistics were found to describe accurately the change in scatter due to the addition of machining chips. This was observed as a decrease in the Weibull modulus with the increase in machining chips addition.

\section{Acknowledgements}

This work was supported by the Region Jönköpings Län and Jönköping University, Sweden, under the
HINT Project (Dnr: HJ2014/3812-431); industrial partners Fagerhult Belysning AB, Lundbergs Pressgjuteri $\mathrm{AB}$, Ventana Hackås (Foundry Division) and Bryne AB are also acknowledged.

Open Access This article is distributed under the terms of the Creative Commons Attribution 4.0 International License (http://creativecommons.org/licenses/by/4.0/), which permits unrestricted use, distribution, and reproduction in any medium, provided you give appropriate credit to the original author(s) and the source, provide a link to the Creative Commons license, and indicate if changes were made.

\section{REFERENCES}

1. J. Campbell, Castings (Elsevier, Amsterdam, 2003), pp. 1-337

2. M. Di Sabatino, S. Akhtar, L. Arnberg, Metall. Sci. Tech. 30(1) (2013)

3. D. Dispinar, J. Campbell, Int. J. Cast Met. Res. 17(5), 287-294 (2004)

4. D. Dispinar, J. Campbell, Int. J. Cast Met. Res. 19(1), 5-17 (2006)

5. G. Timelli, F. Bonollo, Int. J. Cast Met. Res. 20(6), 304-311 (2007)

6. M. Di Sabatino, L. Arnberg, S. Rørvik, A. Prestmo, Mater. Sci. Eng. A 413, 272-276 (2005)

7. A.A. Simard, F. Dallaire, J. Proulx, P. Rochette, in Light Metals (2000), pp. 739-744.

8. D. Dispinar, J. Campbell, in TMS Annual Meeting (2007)

9. N.R. Green, J. Campbell, Mater. Sci. Eng. A 173(1-2), 261-266 (1993)

10. M. Tiryakioğlu, D. Hudak, Metall. Mater. Trans. B 42(6), 1130-1135 (2011)

11. C.H. Cáceres, I.L. Svensson, J.A. Taylor, Int. J. Cast Met. Res. 15(5), 531-543 (2003)

12. C.H. Cáceres, B.I. Selling, Mater. Sci. Eng. A 220(1), 109-116 (1996)

13. Premetz Analysis. https://premetz.com/pages/analysis. Accessed 2 Aug 2017

14. J. Campbell, Mater. Sci. Technol. 22(2), 127-145 (2006)

15. M. Riestra, E. Ghassemali, T. Bogdanoff, S. Seifeddine, Mater. Sci. Eng. A 703, 270-279 (2017)

16. T. Ludwig, M. Di Sabatino, L. Arnberg, D. Dispinar, Int. J. Metalcast. 6(2), 41-50 (2012)

17. B.G. Eisaabadi, P. Davami, N. Varahram, S.K. Kim, Mater. Sci. Eng. A 565, 278-284 (2013)

18. B.G. Eisaabadi, P. Davami, S.K. Kim, M. Tiryakioğlu, Mater. Sci. Eng. A 579, 64-70 (2013) 